http://jmscr.igmpublication.org/home/

ISSN (e)-2347-176x ISSN (p) 2455-0450

crossref DOI: https://dx.doi.org/10.18535/jmscr/v7i7.67

\title{
Efficacy and safety of radio frequency in acne and freckles
}

\author{
Authors \\ Dr Rashmi Singh ${ }^{1 *}$, Dr (Prof) Rana Gopal Singh ${ }^{2}$ \\ Department of Dermatology, Heritage Institute of Medical Sciences, Bhadwar bypass, Varanasi, \\ Uttar Pradesh \\ *Corresponding Author \\ Dr Rashmi Singh \\ C-33/58B2K, Behind sunbeam school, Sigra, Varanasi, UP, India
}

\begin{abstract}
Context: Acne has become one of the most commonly treated skin conditions by a practicing dermatologists accounting for approximately $80 \%$ cases. While freckles is common among Fitzpatrick skin type 1-3, acne can occur in all skin types. RF (radiofrequency) is slowly gaining popularity in treating both the conditions especially the monopolar non ablative ones.

Aim: To find the efficacy and safety of radiofrequency in acne as well as freckles.

Setting and Design: It is a randomized controlled trial with split face study.

Material \& Methods: 25 patients in each group were enrolled for the split face study. In both acne \& freckles group lesions on half of the face had undergone RF treatment and rest half treated with topical tretinoin MS 0.04\% in acne patients once application at night \& 20\% TCA in freckles group.

Result: While $85 \%$ patients in acne group had shown excellent response, in freckles group excellent response was seen in $77.78 \%$ patients and rest $15 \%$ in group $A \& 22.22 \%$ in group $F$ had shown modest response.

Conclusion: From this study it can be concluded that $R F$ is a safe and faster treatment modality for both acne and freckles thereby avoiding the systemic side effects of oral agents in acne and lesser chances of recurrence in both groups of patients.
\end{abstract}

Keywords: Acne, freckles, RFA, split face stud

Keymessage: Acne \& freckles can be effectively treated by $R F$.

\section{Introduction}

Acne vulgaris has always been a major cosmetic concern for adolescents and adults. While many therapies are available for its treatment, nonresponsive acne, side effects and antibiotic resistance are the problems faced by the dermatologists in treating them. Freckles are melanocytic lesions though more frequently seen in the Fitzpatrick skin type $1 \& 2$ but also seen type 3-5 with red or blond hair. Recently, radiofrequency ablation and light therapy has gained importance in treatment of both freckles and acne, with minimal side effects and quicker response. By unknown mechanisms, RFA decreases the size of the sebaceous glands, pilosebaceous inflammation, and inhibit growth of Demodex and Propionibacterium species in acne patients $^{1,2}$. Further, in freckles it works by destruction of melanocytes. While most studies have focused on either treatment of acne scars 
with RFA or combining light therapy with RFA for treatment of acne, our study has used only radiofrequency ablation for treatment of acne and freckles. The electric current produced by RF devices use electromagnetic radiation in the frequency range of $3 \mathrm{kHz}$ to $300 \mathrm{MHz}^{3,4,5}$. The unipolar RF can be differenciated from monopolar $\mathrm{RF}$ in that former does not deliver an electric current to the skin. ${ }^{6}$ The main difference between bipolar and monopolar $\mathrm{RF}$ is that while the monopolar RF devices have one active electrode placed on the skin and a grounding electrode. bipolar one consists of two active electrodes placed apart over the intended treatment area ${ }^{7}$

\section{Subjects and Methods}

After getting ethical clearance from the reviewing committee of my institute, based on the prevalence of both acne and freckles in dermatology opd of the institute, 25 consecutive patients were selected for the split face study comparing two different modalities on different sides of face. The side of face to which either of treatments was applied was selected randomly. Both groups A (acne) \& F (freckles) were subjected to a split face study with half of face in each group treated at weekly intervals for 4 weeks with RF of monopolar type with sharp tipped diamond shaped electrode delivering energy at $2 \mathrm{~J}$ $/ \mathrm{cm}^{3}$ whereby dessication method was used with tip just touching the tissue. Other half of face in group A were subjected to topical $0.04 \%$ tretinoin with microsphere technology once daily at night $\& 20 \%$ TCA in group F and sun protection with broad spectrum sunscreen in both the groups. The acne and freckle groups were thereafter followed up monthly for 6 months and photographed using smart phone with 16 mega pixel camera at each visit and assessment done using Global Acne Grading System (GAGS) in acne and that of freckles by FASI scoring (freckles assessement scoring index). Pregnant and nursing mothers, those on oral retinoids and steroids (topical and oral) in last 1 month and those with pacemakers were excluded from the study.

\section{Procedure}

An eutectic mixture of local anesthetics (EMLA) c ream that contains $2.5 \%$ lidocaine and $2.5 \%$

prilocaine. It was applied under occlusion to skin at least an hour before the procedure to achieve topical anesthesia. Post procedure: patients were instructed to: a) Avoid sun exposure, b) Application of Physical sunscreens and topical antibiotics for 5 days.

\section{Result}

Out of 25 patients who were enrolled in acne group (GROUPA), 20 completed the study,3 were lost to follow up and 2 dropped out because of erythema and edema after first sitting of treatment. Out of 25 patients in freckles group (GROUPF), 18 completed the study, 4 were lost to follow up and 3 dropped out after 2 sessions (2 weeks) because of post-inflammatory hyperpigmentation. Patients recorded the adverse effects (hyperpigmentation, erythema, edema, blisters, crusting, pain) for 7 days after the initial treatment and we verified and assessed the same for severity at each treatment session. The overall improvement of patients was assesed according to the following scale: modest, and excellent. Patients in group A were of age range (15-25 years) \& in group F (20-35years). Males were 8 and 5 in number respectively in groups $\mathrm{A} \& \mathrm{~F}$ and females were $12 \& 13$ respectively in groups A\& F.While 2 males and 1 female had modest improvement in group A, 6 males and 11 females had excellent response. Though, females outnumber males in excellent response category this is stastically insignificant $(\mathrm{p}>0.05, \mathrm{p}=0.306)$. In group $\mathrm{F}$, while 11 females and 3 males show excellent response, those showing modest response was 2 each in male and female category. Again the difference in response seen in different sex is just a coincidence as pvalue is 0.206 $(>0.05)$. 


\section{JMSCR Vol||07||Issue ||07||Page 362-368||July}

Table 1 Epidemiological parameters of acne and freckles patients

\begin{tabular}{c|cc}
\hline $\begin{array}{c}\text { Epedimiological } \\
\text { parameters }\end{array}$ & Acne (Group A) & Freckles (Group F) \\
\hline Age & $15-25$ & $\mathbf{2 0 - 3 5}$ \\
Males & 08 & $\mathbf{0 5}$ \\
Females & 12 & $\mathbf{1 3}$ \\
Previously Treated & 15 & $\mathbf{1 6}$ \\
Previously untreated & 05 & $\mathbf{0 2}$ \\
\hline
\end{tabular}

Table 2: Improvement in acne and freckles

\begin{tabular}{|c|c|c|c|c|}
\hline Disease & & Acne & \multicolumn{2}{|c|}{ Freckles } \\
\hline Improvement & Modest & Excellent & Modest & Excellent \\
\hline Male & 02(25) & $06(75)$ & $02(40)$ & $03(60)$ \\
\hline Female & $01(8.33)$ & 11(91.67) & $02(15.38)$ & $11(84.615)$ \\
\hline P value & 0.306 & & \multicolumn{2}{|c|}{0.261} \\
\hline
\end{tabular}

Table 3 Side effects during 7 days observation and at weekly treatment visits in acne patients

\begin{tabular}{l|cllc}
\hline Weekly observation & 1week & 2week & 3week & 4week \\
\cline { 1 - 4 } Side effects & & & & \\
Hyperpigmentation & $\mathbf{0}$ & $\mathbf{0 1}$ & $\mathbf{0 2}$ & $\mathbf{0 2}$ \\
Erythema & $\mathbf{0}$ & $\mathbf{0}$ & $\mathbf{0}$ & $\mathbf{0}$ \\
Edema & $\mathbf{2}$ & $\mathbf{0}$ & $\mathbf{0}$ & $\mathbf{0}$ \\
\hline
\end{tabular}

Table 4: Side effects in freckles group

\begin{tabular}{lcccc}
\hline Weekly observation & $1^{\text {st }}$ week & 2nd week & $3^{\text {rd }}$ week & $4^{\text {th }}$ week \\
\hline Erythema & 3 & 0 & 0 & 0 \\
Edema & 12 & 0 & 0 & 0 \\
Crusting & 18 & 0 & 0 & 0 \\
Hyperpigmentatiom & 0 & 1 & 2 & 2 \\
\hline
\end{tabular}

Table 5: Response to treatment in groups A\&F at monthly follow up ( $\mathrm{Z}$ score two tailed)

\begin{tabular}{|c|c|c|c|}
\hline Monthly follow & Acne group A & Freckles group $\mathrm{F}$ & pvalue \\
\hline GROUP & & & \\
\hline $1^{\mathrm{st}}$ & 12 & 16 & 0.0433 (significant) \\
\hline $2^{\text {nd }}$ & 14 & 17 & 0.0524 \\
\hline $3^{\text {rd }}$ & 14 & 17 & 0.0524 \\
\hline $4^{\text {th }}$ & 18 & 18 & 0.1675 \\
\hline $5^{\text {th }}$ & 20 & 18 & 0 (significant) \\
\hline $6^{\text {th }}$ & 20 & 18 & 0 (significant) \\
\hline
\end{tabular}

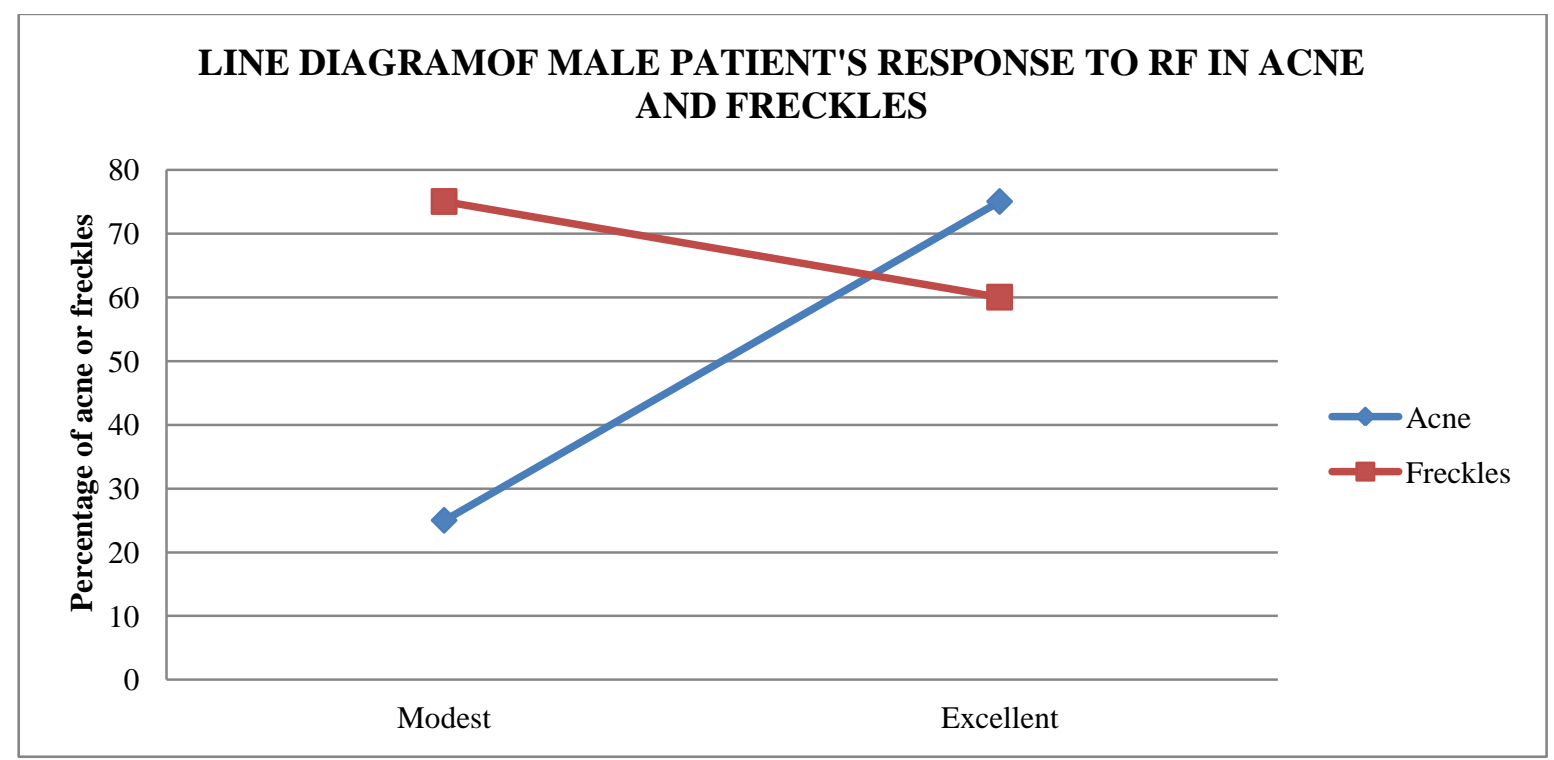




\section{JMSCR Vol||07||Issue ||07||Page 362-368||July}

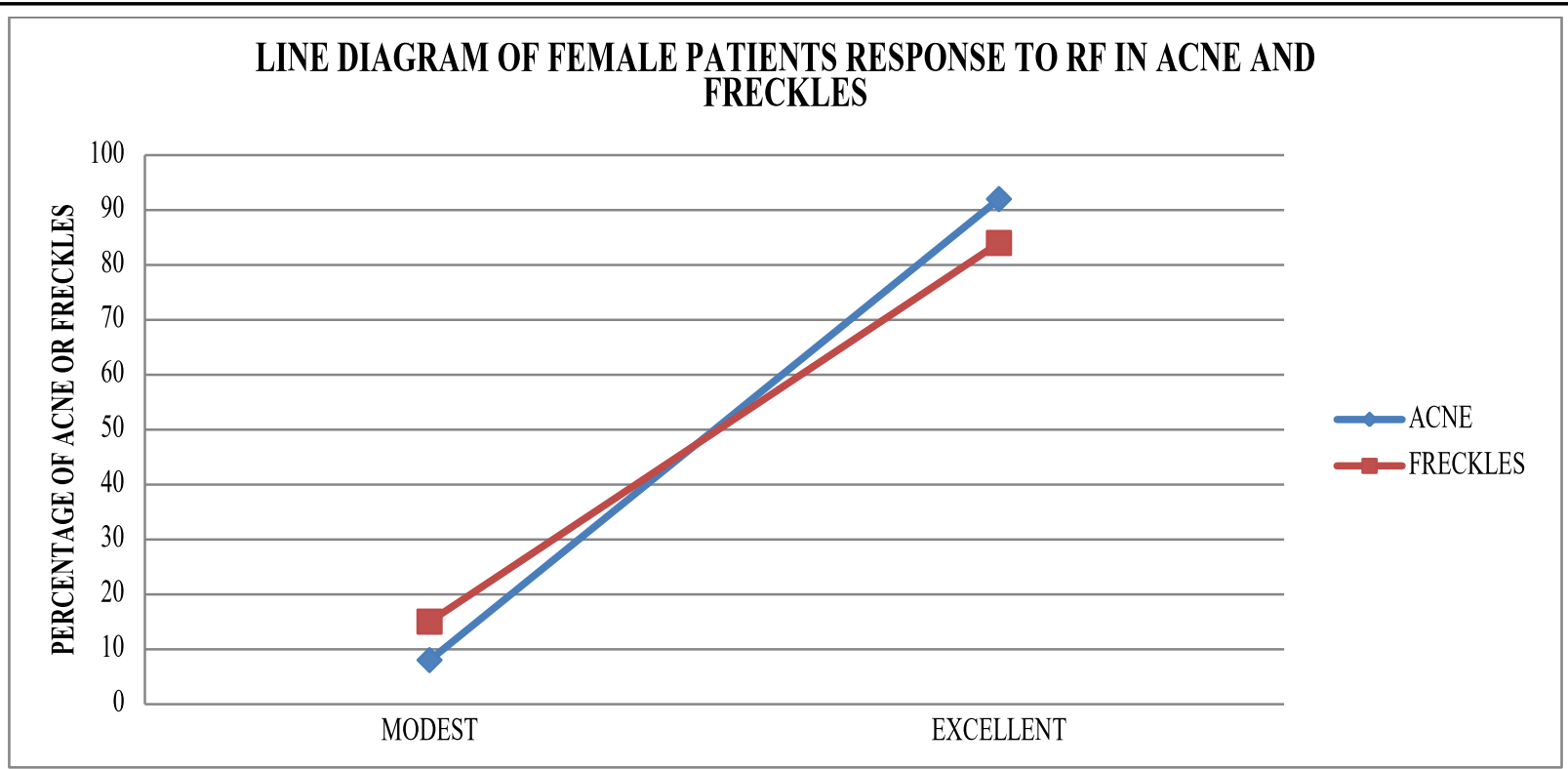

Look at the graphs $(1,2)$, showing excellent response in either of sexes in case of both acne and freckles. What do these photos show?

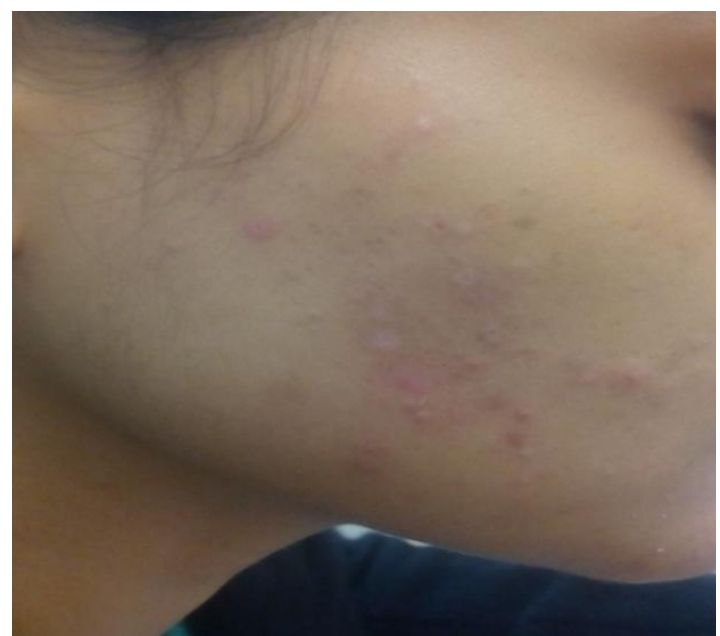

1 Month Post RFA

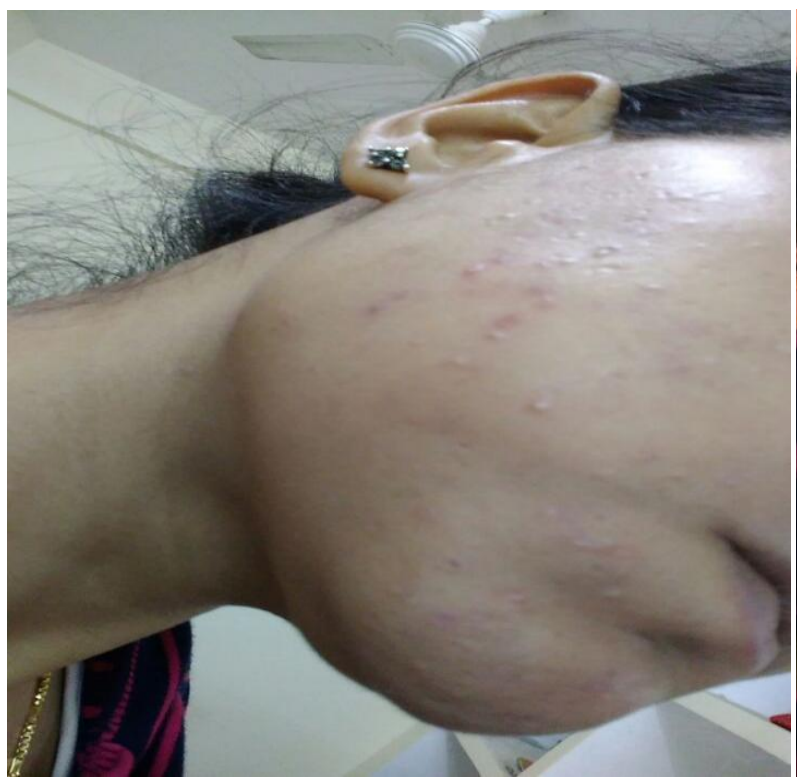

4 Months Post RFA

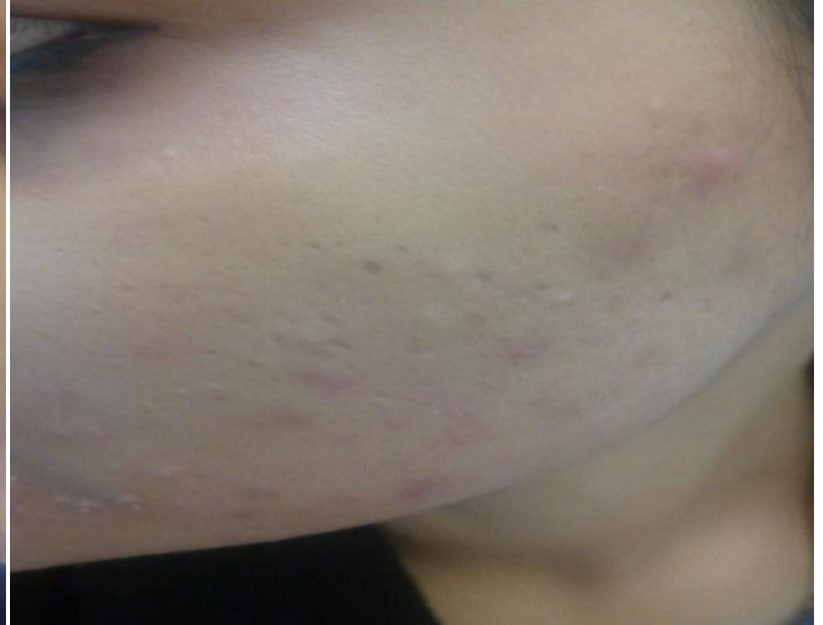

1 Month Post Retinoid

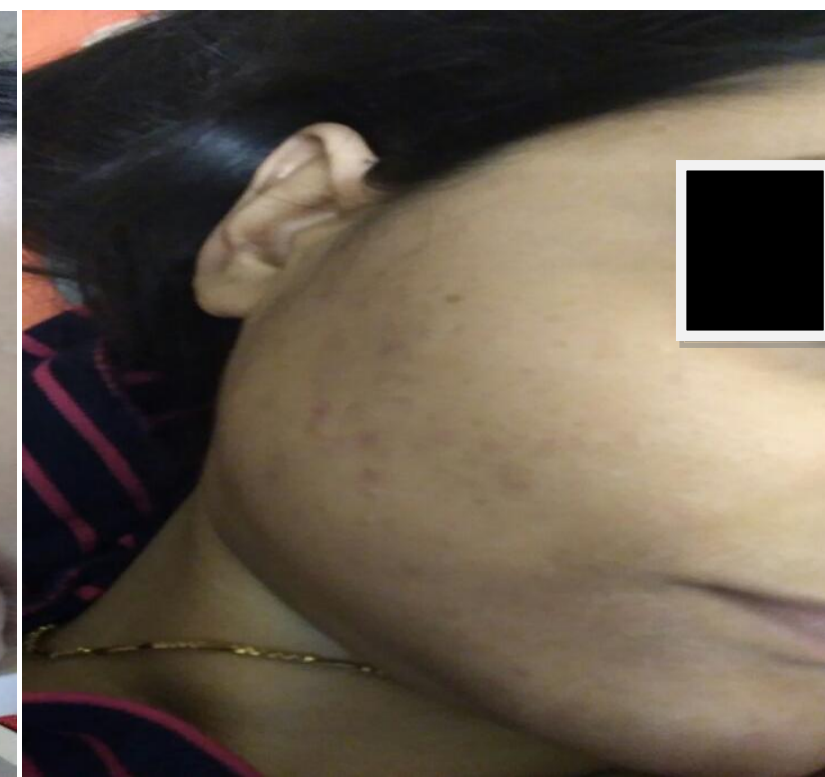

8 Months Post RFA 


\section{JMSCR Vol||07||Issue ||07||Page 362-368||July}

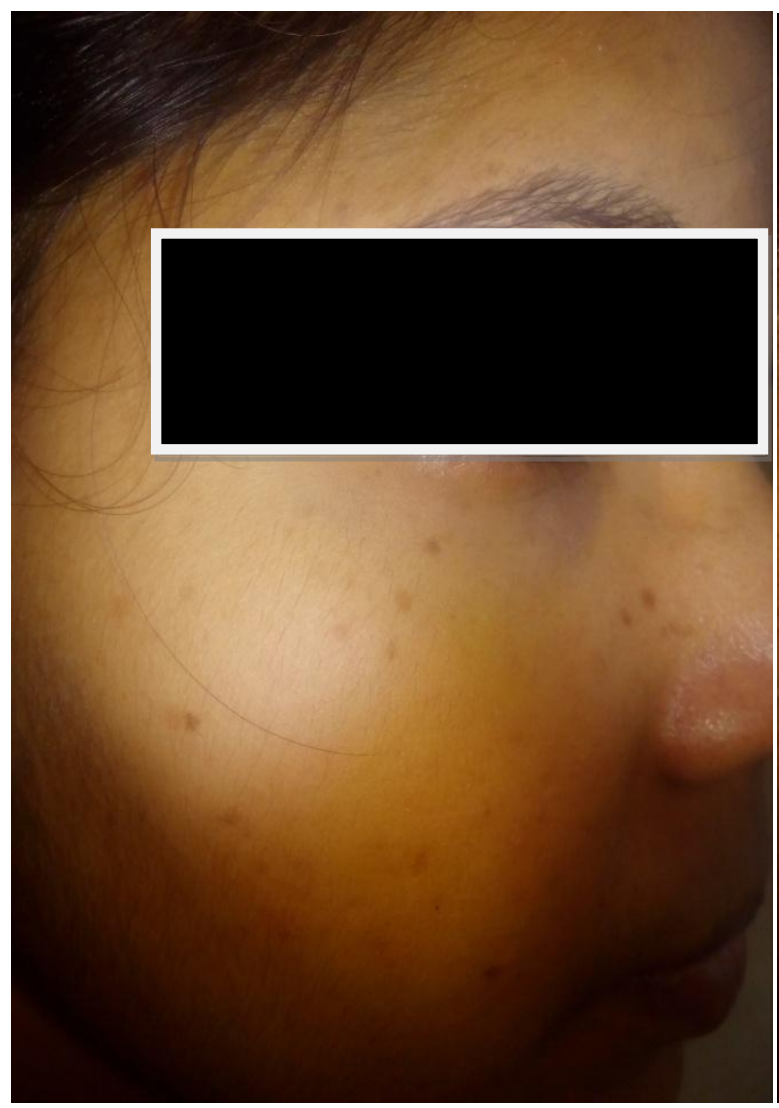

Freckles Pre RFA

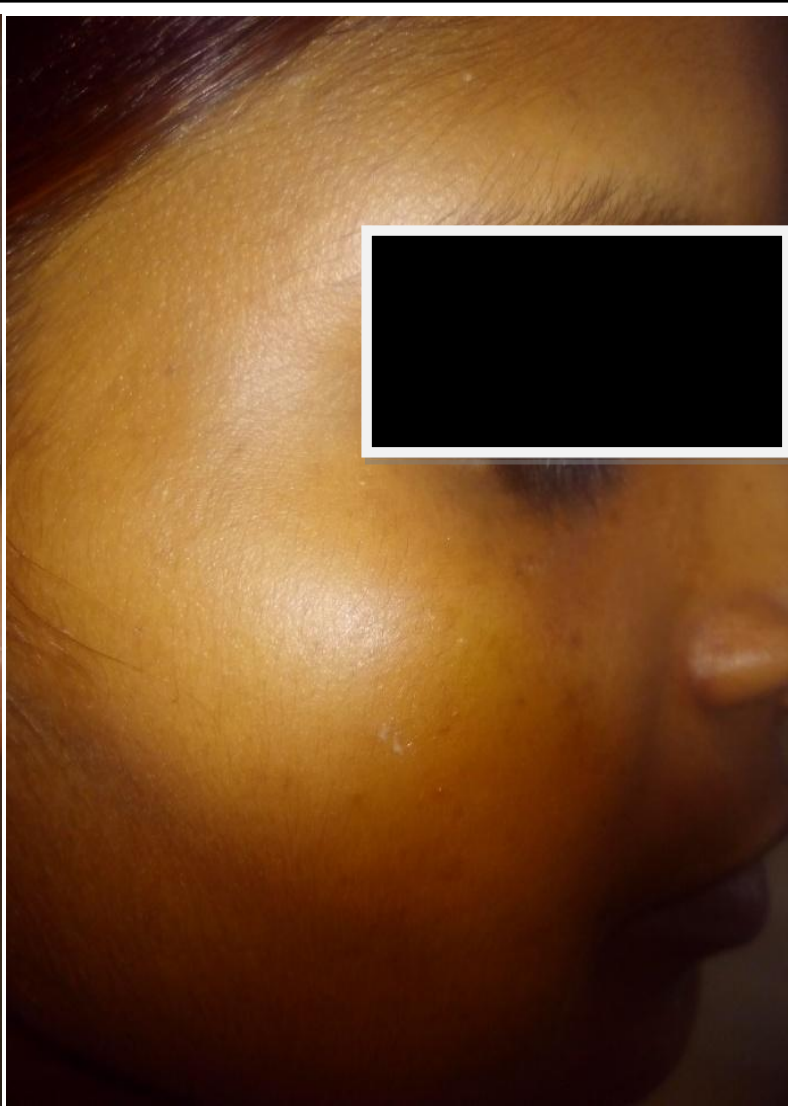

Freckles 2 Months Post RFA

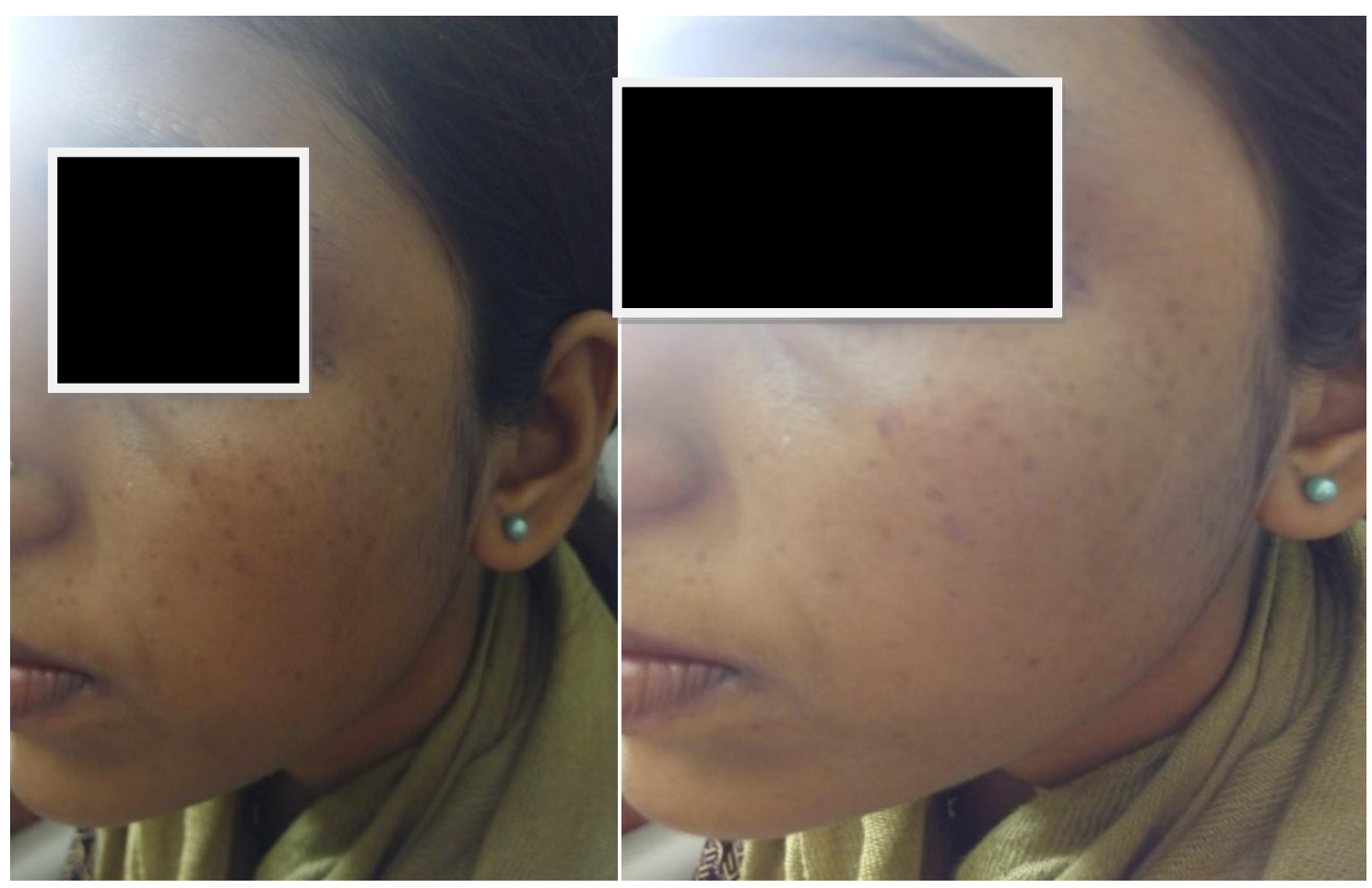

2 Weeks Post Retinoid

2 Months Post Retinoid

First 4 photos show acne patient of which $2^{\text {nd }}$ one is of same patient with her left face on retinoid treatment. Next two photos show freckles patient on radiofrequency treatment with excellent response and last two of freckles patient on retinoid on left face showing very less improvement with retinoidat 2 months. 


\section{Discussion}

Till now, most light and laser procedures have focussed on pigmented lesions, vascular lesions, skin texture, and fine lines, and most have been performed on non-inflammatory skin (e.g., acne scars $)^{8,9,10}$. But recently, such procedures are being developed for treating inflammatory skin conditions also such as acne. In addition, the efficacy of light, laser, RF and photodynamic therapies, as well as the mechanism by which light devices destroy acne, have been reported. ${ }^{11}$

Till date most studies have used fractional radiofrequency for the treatment of both acne and acne scars. ${ }^{12}$ In contrast, our study has used simple non- fractional radiofrequency for the treatment of acne lesions with $75 \%$ males \& $91.67 \%$ females patients showing excellent improvement so in all $85 \%$ patients have shown excellent response.

In a study done by Ruiz Esparza, Javier Md; Gomez, Julio Barbarain 2003, where nonablative radiofrequency was used for delivering deep dermal heat for treatment of active acne vulgaris, out of 22 Patients excellent response was seen in $82 \%(\mathrm{n}=18)$ and modest and no response respectively in $9 \%$ each which was quite consistent with our findings ${ }^{13}$

As of now RF pulsed light devices with ELOS technology (electro-optical synergy) are being used to treat acne vulgaris. One such study of the Aurora system on 32 patients with moderate inflammatory acne revealed clinical improvement as evidenced by a reduction in lesion count, decrease in size of the sebaceous glands, and reduction in perifollicular lymphocytic infiltrates with very few side effects e.g. erythema, tingling, and burning ${ }^{14}$. In yet another study using the Aurora system for acne scars out of three patients $50 \%$ improvement was noted in one and $25-50 \%$ in other two. ${ }^{15}$

What was done in the past? Till now studies have focussed more on RF treatment of acne scars that too using fractional RF which is costlier. As far as freckles is concerned sufficient studies on use of $\mathrm{RF}$ are lacking.
What's new in this study? Our study uses nonfractional RF for the treatment of acne which is an inflammatory condition and freckles which is both resistant to the presently available depigmenting agent \& a late responder.

\section{Conclusion}

The need of the hour is to discourage long term use of antibiotics which is leading to resistence in patients of acne and oral retinoids which too is not free from side effect and encourage the use of RF $-\mathrm{a}$ faster and safer treatment. Similarly in freckles patients can be treated with RF initially and kept on mild depigmenting agents like kojitin and sunscreen to prevent relapse.

\section{Acknowledgement}

Foremost, I would like to thank the ethical committee of my college for giving me a chance to do this research.

A very special and sincere gratitude goes to my advisor and my coinvestigator Dr (Prof) R G Singh for his continuous support and guidance throughout study period.

I wish to express my thanks to $\operatorname{Dr}$ (Prof) MS Siddique who has guided me in writing this research .

I want use this opportunity to thank my junior resident Dr. Achlesh for his cooperation during this study.

Last but not least I would like to show my gratitude to my husband Dr Rakesh Chandra Chaurasia and my Parents who have always stood by my side for the motivational support during study.

\section{Sources of support in the form of grants: No.}

\section{Reference}

1. Kim ST, Lee KH, Sim HJ, Suh KS, Jang MS. Treatment of acne vulgaris with fractional radiofrequency microneedling. The Journal of dermatology. 2014 Jul 1;41(7):586-91. 
2. Fien S, Ballard CJ, Nouri K. Multiple modalities to treat acne: A review of lights, lasers and radiofrequency. Cosmet Dermatol. 2004; 17:789-93.

3. El-Domyati M, El-Ammawi TS, Medhat W, Moawad O, Brennan D, Mahoney MG, Uitto J. Radiofrequency facial rejuvenation: evidence-based effect. Journal of the American Academy of Dermatology. 2011 Mar 31;64(3):524-35.

4. Alexiades-Armenakas M, Dover JS, Arndt KA. Unipolar versus bipolar radiofrequency treatment of rhytides and laxity using a mobile painless delivery system. Lasers Surg Med 2008;40:44653.

5. Elsaie ML. Cutaneous remodeling and photorejuvenation using radiofrequency devices. Indian J Dermatol 2009;54:201-5.

6. Lolis MS, Goldberg DJ. Radiofrequency in cosmetic dermatology: a review. Dermatologic Surgery. 2012 Nov 1;38(11):1765-76.

7. Alster RS, Lupton JR. Nonablative cutaneous remodeling using radiofrequency devices. Clin Dermatol 2007;25:487-91.

8. Rogachefsky AS, Hussain M, Goldberg DJ. Atrophic and a mixed pattern of acne scars improved with a 1320-nm Nd: YAG laser. Dermatologic surgery. 2003 Sep 1;29(9):904-8.

9. Sadick NS, Schecter AK. A preliminary study of utilization of the 1320-nm Nd: YAG laser for the treatment of acne scarring. Dermatologic surgery. 2004 Jul 1;30(7):995-1000.

10. Patel N, Clement M. Selective nonablative treatment of acne scarring with $585 \mathrm{~nm}$ flashlamp pulsed dye laser. Dermatologic surgery. 2002 Oct 1;28(10):942-5.
11. Ruiz-Esparza J, Gomez JB. Nonablative radiofrequency for active acne vulgaris: the use of deep dermal heat in the treatment of moderate to severe active acne vulgaris (thermotherapy): a report of 22 patients. Dermatologic surgery. 2003 Apr 1;29(4):333-9.

12. Montesi G, Calvieri S, Balzani A, Gold $\mathrm{MH}$. Bipolar radiofrequency in the treatment of dermatologic imperfections: clinicopathological and immunohistochemical aspects. Journal of drugs in dermatology: JDD. 2007 Sep;6(9):890-6.

13. Prieto VG, Zhang PS, Sadick NS. Evaluation of pulsed light and radiofrequency combined for the treatment of acne vulgaris with histologic analysis of facial skin biopsies. Journal of cosmetic and laser therapy. 2005 Jan 1;7(2):63-8.

14. Köse O. Successful removal of freckles with the bipolar radiofrequency and optical energy. Journal of Cosmetic and Laser Therapy. 2016 May 18;18(4):230-3. 